Research Paper

\title{
Comparisons of Pressure-controlled Ventilation with Volume Guarantee and Volume-controlled 1:1 Equal Ratio Ventilation on Oxygenation and Respiratory Mechanics during Robot-assisted Laparoscopic Radical Prostatectomy: a Randomized-controlled Trial
}

\author{
Min-Soo Kim, Sarah Soh, So Yeon Kim, Min sup Song, Jin Ha Park ${ }^{\bowtie}$ \\ Department of Anesthesiology and Pain Medicine, and Anesthesia and Pain Research Institute, Yonsei University College of Medicine, Seoul, Republic of Korea. \\ $\triangle$ Corresponding author: Jin Ha Park, MD. PhD. Department of Anesthesiology and Pain Medicine and Anesthesia and Pain Research Institute, Yonsei \\ University College of Medicine, 50 Yonsei-ro, Seodaemun-gu, Seoul, 03722, Republic of Korea. Phone: 82-2-2228-2420; Fax: 82-2-312-7185; E-mail: \\ realsummer@yuhs.ac \\ (C) Ivyspring International Publisher. This is an open access article distributed under the terms of the Creative Commons Attribution (CC BY-NC) license \\ (https://creativecommons.org/licenses/by-nc/4.0/). See http://ivyspring.com/terms for full terms and conditions.
}

Received: 2018.07.10; Accepted: 2018.09.06; Published: 2018.10.20

\begin{abstract}
Background: During robot-assisted laparoscopic radical prostatectomy (RALP), steep Trendelenburg position and carbon dioxide pneumoperitoneum are inevitable for surgical exposure, both of which can impair cardiopulmonary function. This study was aimed to compare the effects of pressure-controlled ventilation with volume guarantee (PCV with VG) and 1:1 equal ratio ventilation (ERV) on oxygenation, respiratory mechanics and hemodynamics during RALP.

Methods: Eighty patients scheduled for RALP were randomly allocated to either the PCV with VG or ERV group. After anesthesia induction, volume-controlled ventilation (VCV) was applied with an inspiratory to expiratory (I/E) ratio of 1:2. Immediately after pneumoperitoneum and Trendelenburg positioning, VCV with I/E ratio of 1:1 (ERV group) or PCV with VG using Autoflow mode (PCV with VG group) was initiated. At the end of Trendelenburg position, VCV with I/E ratio of 1:2 was resumed. Analysis of arterial blood gases, respiratory mechanics, and hemodynamics were compared between groups at four times: 10 min after anesthesia induction ( $\mathrm{Tl}$ ), 30 and $60 \mathrm{~min}$ after pneumoperitoneum and Trendelenburg positioning (T2 and T3), and 10 min after desufflation and resuming the supine position (T4).
\end{abstract}

Results: There were no significant differences in arterial blood gas analyses including arterial oxygen tension $\left(\mathrm{PaO}_{2}\right)$ between groups throughout the study period. Mean airway pressure (Pmean) were significantly higher in the ERV group than in the PCV with VG group T2 $(p<0.001)$ and T3 $(p=0.002)$. Peak airway pressure and hemodynamic data were comparable in both groups.

Conclusion: PCV with VG was an acceptable alternative to ERV during RALP producing similar $\mathrm{PaO}_{2}$ values. The lower Pmean with PCV with VG suggests that it may be preferable in patients with reduced cardiovascular function.

Key words: arterial oxygenation, autoflow, equal ratio ventilation, pressure-controlled ventilation with volume guarantee, respiratory mechanics, robot-assisted laparoscopic radical prostatectomy, volume-controlled ventilation

\section{Introduction}

Robot-assisted laparoscopic radical prostatectomy (RALP) has been widely used because it provides many benefits over open procedures [1,2]. However, steep Trendelenburg position and carbon dioxide 
$\left(\mathrm{CO}_{2}\right)$ pneumoperitoneum are inevitably used during RALP to optimize surgical exposure, both of which have a major impact on the cardiovascular and pulmonary systems [3-5]. Combined with $\mathrm{CO}_{2}$ pneumoperitoneum, steep Trendelenburg position increases ventricular filling pressure and airway pressure during positive pressure ventilation, potentially resulting in hypoxia, pulmonary edema, and heart failure [6]. In addition, upward movement of the diaphragm leads to pulmonary atelectasis and reduced functional residual capacity and lung compliance $[7,8]$. Therefore, ventilatory strategies are required to protect the respiratory system and minimize adverse effects of the steep Trendelenburg position and $\mathrm{CO}_{2}$ pneumoperitoneum during RALP.

Inverse inspiratory to expiratory (I/E) ratio ventilation or prolonged I/E ratio ventilation (i.e., a 1:1 ratio) is a mechanical ventilation strategy proposed for improving oxygenation in acute respiratory distress syndrome. By increasing inspiratory time during the respiratory cycle, more alveoli are kept open, with the goal of reducing the occurrence of atelectasis and limiting peak inspiratory pressure (Ppeak). Recent studies, including a meta-analysis, have reported that prolonged I/E ratio ventilation during anesthesia improves respiratory mechanics and oxygenation [9-12]. However, concerns regarding possible intrinsic positive end-expiratory pressure (PEEP) and decreases in cardiac output during prolonged I/E ratio ventilation still limit its clinical application, especially in patients with chronic obstructive pulmonary disease (COPD) $[9,10,13]$.

Pressure-controlled ventilation with volume guarantee (PCV with $\mathrm{VG}$ ) is a type of pressure regulated volume control (PRVC) ventilation modes which has both features of volume-controlled ventilation (VCV) and pressure-controlled ventilation (PCV). PCV with VG can deliver a constant tidal volume with a constant inspiratory pressure, using a decelerating flow pattern. In laparoscopic surgery, PCV might be advocated to maintain sufficient tidal volume and oxygenation against increases in airway pressure after Trendelenburg positioning and $\mathrm{CO}_{2}$ pneumoperitoneum. Previously, PCV alone failed to improve arterial oxygen tension but significantly reduced Ppeak and improved lung compliance compared to VCV during RALP [6]. Therefore, it is necessary to investigate the effects of PCV with VG, which combines the advantages of VCV and PCV on oxygenation and respiratory mechanics in laparoscopic surgery. Comparisons of PCV with VG with prolonged I/E ratio ventilation are needed, as prolonged I/E ratio ventilation has been suggested to improve oxygenation in laparoscopic surgery.
The aim of this study was to compare the effects of PCV with VG and volume-controlled 1:1 equal ratio ventilation (ERV) on gas exchange, respiratory mechanics and hemodynamics in patients undergoing RALP.

\section{Methods}

This prospective randomized double-blind study was conducted at Severance Hospital, Yonsei University Health System, Seoul, Korea, approved by our Institutional Review Board (ref: 4-2017-0400, Chairperson Professor Sun Young Rha) on 24 June 2017, and written informed consent was obtained from all subjects participating in the trial. The trial was registered prior to patient enrollment at www.ClinicalTrials.gov (NCT03202953, principal investigator Jin Ha Park, date of registration: on 29 June, 2017).

\section{Patients}

After obtaining written informed consent from all patients, 80 men between 20 and 80 years of age scheduled for elective RALP using the da Vinci ${ }^{\mathrm{TM}}$ Surgical System (Intuitive Surgical, Inc., Mountain View, CA, USA) under general anesthesia were enrolled in the study. Patients were excluded if they had COPD, reactive airway disease, another pulmonary disease, a left ventriclular ejection fraction $<50 \%$, or obesity (body mass index $>30 \mathrm{~kg} / \mathrm{m}^{2}$ ). We also excluded patients who were unable to read the informed consent form.

Patients were randomly assigned in a 1:1 ratio to either the PCV with VG or ERV group using a computerized randomization table by an investigator not involved in patient care. For each patient, anesthetic care was provided in the same manner by an independent, experienced anesthesiologist. The attending anesthesiologists were aware of the group assignment, but the patients, urologists, and outcome assessors were blinded to group assignment.

\section{Anesthetic management}

Upon arrival at the operating room, standard monitoring devices were applied. General anesthesia was induced with intravenous propofol $1.5 \mathrm{mg} / \mathrm{kg}$, desflurane at an end-tidal concentration of 5\%-6\% with $100 \%$ oxygen, and an intravenous remifentanil infusion at $0.5-1 \mu \mathrm{g} / \mathrm{kg} / \mathrm{min}$. Intravenous rocuronium $0.6 \mathrm{mg} / \mathrm{kg}$ was used for neuromuscular blockade to facilitate intubation. After endotracheal intubation, anesthesia was maintained with desflurane at an end-tidal concentration of $5 \%-6 \%$ in an air-oxygen mixture (fraction of inspired oxygen $=0.5$ ) and a remifentanil infusion at $0.1-0.3 \mu \mathrm{g} / \mathrm{kg} / \mathrm{min}$. The depth of anesthesia was adjusted to maintain the bispectral 
index score (BIS) (A-2000 BIS Monitor ${ }^{\mathrm{TM}}$; Aspect Medical System Inc., Newton, MA) between 40 and 60. A continuous infusion of intravenous rocuronium $0.6 \mu \mathrm{g} / \mathrm{kg} / \mathrm{h}$ was administered throughout surgery. The radial artery was cannulated after anesthesia induction for continuous blood pressure monitoring and arterial blood sampling. Mean arterial pressure (MAP) and heart rate (HR) were maintained within approximately $20 \%$ of baseline. At the end of surgery, all anesthetic agents were discontinued, oxygen $100 \%$ was administered and residual neuromuscular blockade was antagonized with sugammadex 4 $\mathrm{mg} / \mathrm{kg}$.

\section{Intervention (ventilation management)}

Immediately after induction, patients were ventilated with VCV mode using an I/E ratio of 1:2, a tidal volume of $8 \mathrm{~mL} / \mathrm{kg}$ ideal body weight, no PEEP, and an inspiratory pause of $10 \%$. Ideal body weight was calculated using the following formula for men: $50+0.91$ (height $[\mathrm{cm}]-152.4$ ) [14]. After $\mathrm{CO}_{2}$ pneumoperitoneum was established with an intra-abdominal pressure of $15 \mathrm{mmHg}$ in the supine position, each patient was placed in a $30^{\circ}$ Trendelenburg position and the ventilation mode was adjusted according to the group allocation. In the PCV with VG group, the ventilation mode was changed from VCV to Autoflow mode by Primus ${ }^{\circledR}$ anesthesia machine (Dräger, Lübeck, Germany) using the same initial setting. In the ERV group, the I/E ratio was changed from 1:2 to 1:1, while maintaining but the other initial setting. At the end of surgery, immediately after $\mathrm{CO}_{2}$ desufflation and resumption of the supine position, the ventilation mode was changed to back to $\mathrm{VCV}$ with an I/E ratio of 1:2 for all patients. The respiratory rate was adjusted to maintain an end-tidal $\mathrm{CO}_{2}$ $\left(\mathrm{ETCO}_{2}\right)$ between 35 and $45 \mathrm{mmHg}$ throughout surgery in both groups. Patients were withdrawn from the study if more than $40 \mathrm{~cm} \mathrm{H}_{2} \mathrm{O}$ of Ppeak was required to maintain the tidal volume or if oxygen desaturation $\left(\mathrm{SpO}_{2}<95 \%\right)$ occurred.

\section{Clinical evaluations}

The primary end point was the level of arterial oxygen tension $\left(\mathrm{PaO}_{2}\right)$ measured at $30 \mathrm{~min}$ after the initiation of the Trendelenburg position. The secondary end points were arterial blood gas analysis (ABGA) results, respiratory mechanics data and hemodynamics data, which were collected at four times: 10 min after anesthesia induction, while in the supine position (T1); $30 \mathrm{~min}$ after initiation of the Trendelenburg position and $\mathrm{CO}_{2}$ pneumoperitoneum (T2); 60 min after initiation of the Trendelenburg position and $\mathrm{CO}_{2}$ pneumoperitoneum (T3); and 10 min after $\mathrm{CO}_{2}$ desufflation and resumption of the supine position (T4). Arterial $\mathrm{pH}, \mathrm{PaO}_{2}$, arterial carbon dioxide tension $\left(\mathrm{PaCO}_{2}\right)$ levels were obtained from the ABGA results. Respiratory mechanics included Ppeak, plateau airway pressure (Pplat), mean airway pressure (Pmean), static compliance (Cstat), $\mathrm{ETCO}_{2}$, and respiratory rate, which were measured by the Primus ${ }^{\circledR}$ anesthesia machine (Dräger, Lübeck, Germany). Hemodynamic data included $\mathrm{MAP}, \mathrm{HR}$, and $\mathrm{SpO}_{2}$. Intraoperative data, such as duration of surgery, volume of fluid and blood administered, urine output, blood loss, and use of vasoactive drugs, were recorded. Postoperative data, including duration of postoperative hospital stay and postoperative complications, were also assessed.

\section{Statistical analysis}

Sample size was calculated based on the results of a previous study comparing VCV with an I/E ratio of 1:1 versus 1:2 during RALP [11]. In that study, $\mathrm{PaO}_{2}$ at $30 \mathrm{~min}$ after initiation of the Trendelenburg position was $167 \pm 32 \mathrm{mmHg}$ in the 1:1 group. We considered a difference of $15 \%(25 \mathrm{~mm} \mathrm{Hg})$ in $\mathrm{PaO}_{2}$ between PCV with VG and ERV with an I/E ratio of 1:1 during VCV as clinically relevant. With a type 1 error $(\alpha)$ of $5 \%$ and power $(1-\beta)$ of $90 \%, 36$ patients were required in each group. Taking into consideration a potential $10 \%$ dropout rate, we decided to enroll 40 patients in each group.

Continuous variables are shown as mean \pm standard deviation or median (interquartile range). Dichotomous variables are expressed as number of patients (percentage). Continuous variables were compared using independent Student's $t$ tests or Mann-Whitney $U$ tests, and dichotomous variables were compared using Chi-square or Fisher's exact tests as appropriate. A linear mixed model with patient indicator as a random effect, and group, time, and group-by-time as fixed effects was used to analyze repeatedly measured variables such as $\mathrm{PaO}_{2}$, $\mathrm{PaCO}_{2}$, Ppeak and Pplat. When interactions of group, time, and group-by-time of variables were statistically significant, post hoc analyses were performed with Bonferroni correction to adjust for multiple comparisons. SPSS 21 (SPSSFW, SPSS, IBM, Armonk, NY, USA) statistical software was used. P values less than 0.05 were considered statistically significant.

\section{Results}

Between July 2017 and January 2018, a total of 80 patients were enrolled in the study. One patient in the PCV with VG group was excluded because endotracheal intubation was difficult and a small endotracheal tube was used. One patient in the ERV group was excluded because of a protocol violation. 
Consequently, 78 patients completed the study (Figure 1). Demographic and perioperative data were similar in the two groups (Table 1).

Table 1. Demographic and perioperative data

\begin{tabular}{|c|c|c|c|}
\hline & $\begin{array}{l}\text { PCV with VG Group } \\
(\mathrm{n}=39)\end{array}$ & $\begin{array}{l}\text { ERV Group } \\
(\mathrm{n}=39)\end{array}$ & P value \\
\hline Age (yr) & $67[62-74]$ & $67[59-71]$ & 0.606 \\
\hline Weight (kg) & 69 [63 - 73] & $67[62-73]$ & 0.697 \\
\hline Height $(\mathrm{cm})$ & 169 [166-172] & 169 [164-171] & 0.700 \\
\hline Body surface area $\left(\mathrm{m}^{2}\right)$ & 1.80 [1.72 - 1.88] & 1.76 [1.70 - 1.83] & 0.234 \\
\hline Hypertension & $14(35.9)$ & $17(43.6)$ & 0.488 \\
\hline Diabetes & $10(25.6)$ & $10(25.6)$ & $>0.999$ \\
\hline Anesthetic time (min) & $175[160$ - 200] & 165 [150 - 185] & 0.120 \\
\hline Operation time (min) & $130[113-149]$ & 119 [104 - 139] & 0.105 \\
\hline $\begin{array}{l}\text { Duration of } \\
\text { Trendelenburg position } \\
\text { (min) }\end{array}$ & 62 [55 - 100] & $61[47-105]$ & 0.455 \\
\hline Fluid intake (ml) & $1650[1450-2100]$ & 1600 [1350 - 1900] & 0.246 \\
\hline Urine output (ml) & $230[100-400]$ & $250[150-400]$ & 0.699 \\
\hline Bleeding (ml) & $300[200-500]$ & $250[100-400]$ & 0.085 \\
\hline Use of vasoconstrictors & $30(76.9)$ & $25(64.1)$ & 0.214 \\
\hline
\end{tabular}

ABGA and $\mathrm{ETCO}_{2}$ data are shown in Table 2. Linear mixed model analysis did not show significant differences between groups for the primary endpoint $\left(\mathrm{PaO}_{2}\right.$ at $30 \mathrm{~min}$ after initiation of $\mathrm{CO}_{2}$ pneumoperitoneum and the Trendelenburg position). There were likewise no significant differences in $\mathrm{ETCO}_{2}$ results or ABGA data throughout the study period between the PCV with VG and ERV groups.

Respiratory data are shown in Table 3 . The interaction of group and time for Pmean was significant between groups in the linear mixed model analysis $(\mathrm{p}=0.038)$. After post hoc analysis with Bonferroni correction, Pmean was noted to be significantly lower in the PCV with VG group at 30 and 60 min after initiation of $\mathrm{CO}_{2}$ pneumoperitoneum and the Trendelenburg position $(\mathrm{p}<0.001$ and $\mathrm{p}=0.002$, respectively). Ppeak, Pplat and Cstat were not different between groups at any time. Hemodynamic data were similar between the two groups (Figure 2).

Postoperative outcomes were comparable between the two groups (Table 4). Eight patients in the PCV with VG group and 11 patients in the ERV group experienced postoperative fever; these rates were not significantly different $(p=0.429)$.

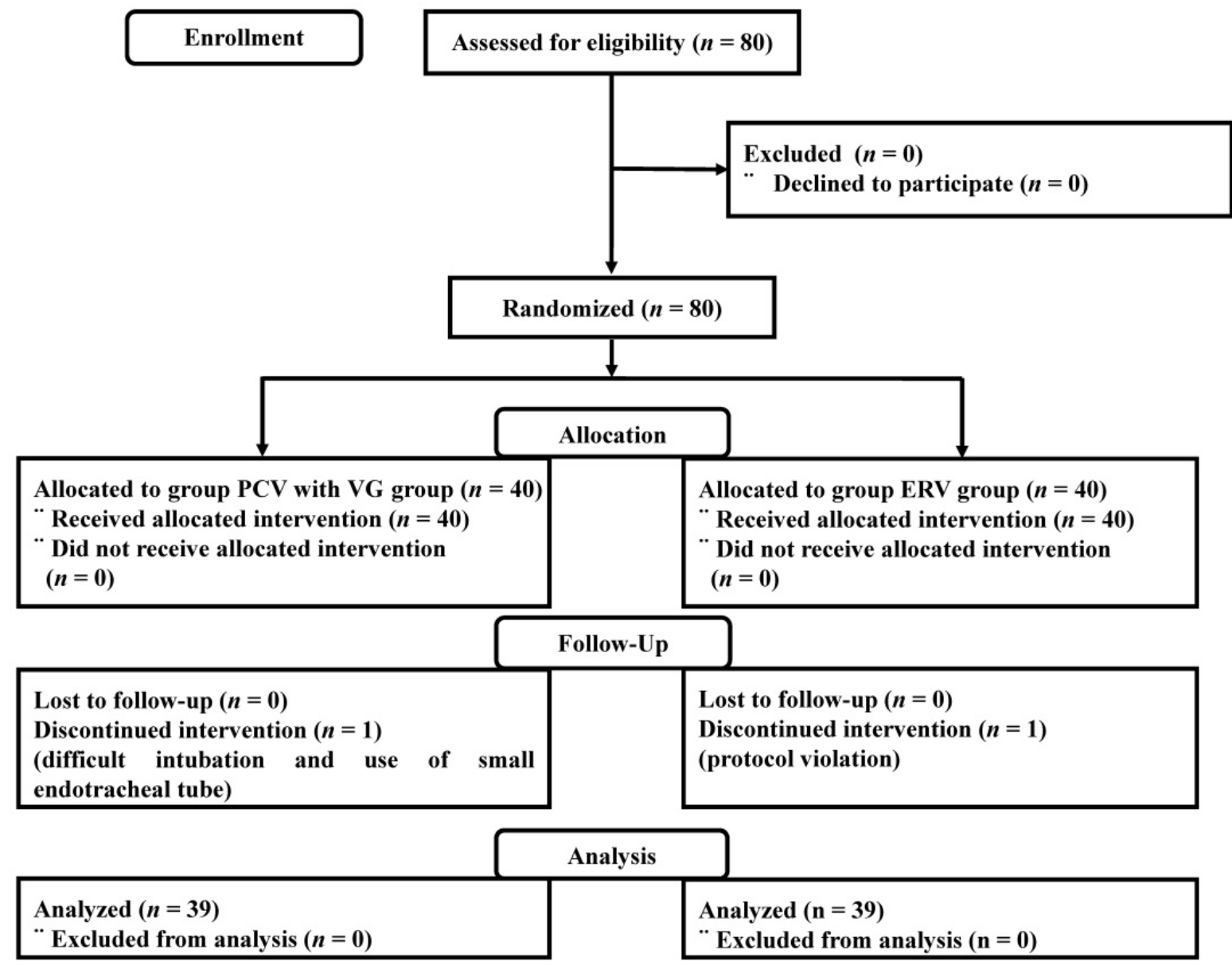

Figure 1. Patient enrolment into the study (using CONSORT recommendations). PCV with VG, pressure-controlled ventilation with volume guarantee; ERV, equal ratio ventilation. 
Table 2. Arterial blood gas analysis and $\mathrm{ETCO}_{2}$ data measured at each time point

\begin{tabular}{|c|c|c|c|}
\hline & $\begin{array}{l}\text { PCV with VG } \\
\text { Group } \\
(n=39)\end{array}$ & $\begin{array}{l}\text { ERV Group } \\
(\mathrm{n}=39)\end{array}$ & Pvalue \\
\hline $\mathrm{pH}$ & & & $0.857 a$ \\
\hline $\mathrm{T} 1$ & 7.43 [7.43 - 7.47] & 7.44 [7.42 - 7.46$]$ & 0.956 \\
\hline $\mathrm{T} 2$ & 7.35 [7.33 - 7.40] & 7.35 [7.32 - 7.38] & 0.294 \\
\hline $\mathrm{T} 3$ & 7.35 [7.32 - 7.38] & 7.35 [7.32 - 7.37] & 0.631 \\
\hline $\mathrm{T} 4$ & 7.35 [7.31 - 7.38] & 7.33 [7.31 - 7.37] & 0.353 \\
\hline $\mathrm{PaO}_{2}(\mathrm{mmHg})$ & & & $0.122^{\mathrm{a}}$ \\
\hline $\mathrm{T} 1$ & 185.6 [160.3 - 218.3] & 177.8 [152.3 - 214.8] & 0.635 \\
\hline $\mathrm{T} 2$ & 176.8 [142.9 - 196.3] & 181.0 [159.0 - 208.7] & 0.366 \\
\hline $\mathrm{T} 3$ & 191.9 [162.3 - 209.3] & 180.3 [156.6 - 203.7] & 0.723 \\
\hline $\mathrm{T} 4$ & 188.9 [161.6 - 203.4] & 196.7 [170.7 - 210.4] & 0.157 \\
\hline $\mathrm{PaCO}_{2}(\mathrm{mmHg})$ & & & $0.593^{a}$ \\
\hline $\mathrm{T} 1$ & $32.5[30.0-34.5]$ & 32.8 [30.7 - 35.5] & 0.265 \\
\hline $\mathrm{T} 2$ & 41.8 [36.9 - 47.8] & $44.6[38.4-48.2]$ & 0.094 \\
\hline T3 & $41.3[37.3$ - 45.2] & $44.1[40.9$ - 47.4$]$ & 0.077 \\
\hline $\mathrm{T} 4$ & $42.2[38.9$ - 49.2$]$ & 48.5 [40.2 - 51.6] & 0.165 \\
\hline $\mathrm{ETCO}_{2}(\mathrm{mmHg})$ & & & $0.846^{\mathrm{a}}$ \\
\hline $\mathrm{T} 1$ & 34 [32 - 36] & $34[33-36]$ & 0.896 \\
\hline $\mathrm{T} 2$ & $39[37-43]$ & $42[37-45]$ & 0.074 \\
\hline $\mathrm{T} 3$ & $41[37-43]$ & $41[38-44]$ & 0.632 \\
\hline $\mathrm{T} 4$ & $41[39-45]$ & 43 [39 - 47] & 0.336 \\
\hline \multicolumn{4}{|c|}{$\begin{array}{l}\text { Data are presented as median (interquartile range). PCV with } \mathrm{VG} \text {, } \\
\text { pressure-controlled ventilation with volume guarantee; } \mathrm{ETCO}_{2} \text {, end-tidal carbon } \\
\text { dioxide; } \mathrm{ERV}, 1: 1 \text { equal ratio ventilation; } \mathrm{PaO}_{2} \text {, arterial oxygen tension; } \mathrm{PaCO}_{2} \text {, } \\
\text { arterial carbon dioxide tension; } \mathrm{T} 1,10 \mathrm{~min} \text { after anaesthesia induction under supine } \\
\text { position; } \mathrm{T} 2,30 \mathrm{~min} \text { after initiation of } \mathrm{CO}_{2} \text { pneumoperitoneum and Trendelenburg } \\
\text { position; } \mathrm{T} 3,60 \mathrm{~min} \text { after initiation of } \mathrm{CO}_{2} \text { pneumoperitoneum and Trendelenburg } \\
\text { position; } \mathrm{T} 4,10 \mathrm{~min} \text { after } \mathrm{CO}_{2} \text { desufflation and resuming the supine position. } \\
\text { *P-value of time and group interaction derived from the linear mixed model. a }{ }_{\text {group }} \\
\text { × time }=\mathrm{P} \text { value of the group and time interaction obtained by linear mixed model } \\
\text { analysis. }\end{array}$} \\
\hline
\end{tabular}

(A)

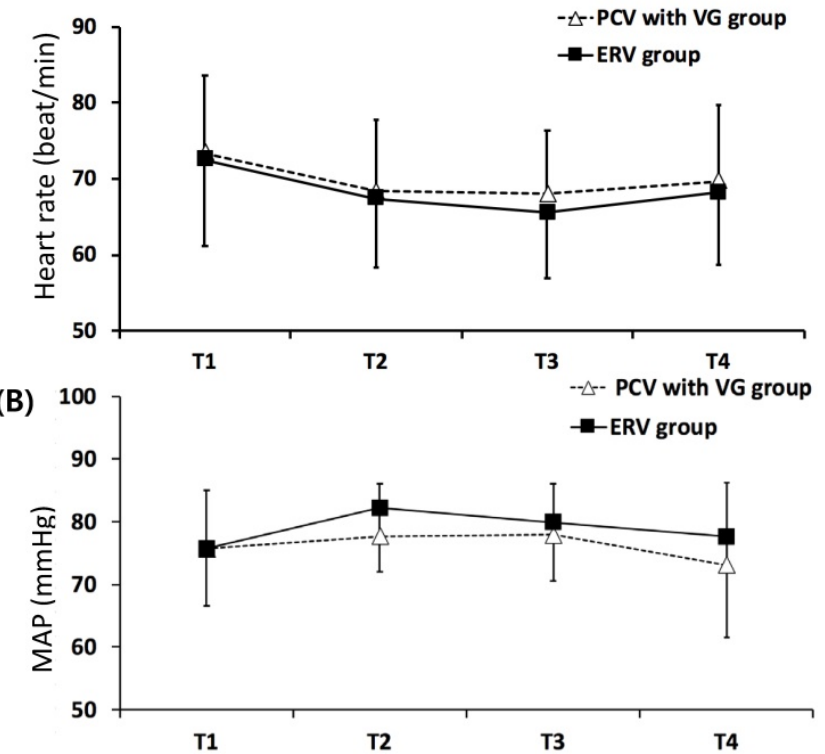

Figure 2. Perioperative hemodynamic variables. Values are mean \pm standard deviation. PCV with VG, pressure-controlled ventilation with volume guarantee; ERV, equal ratio ventilation; MAP, mean arterial pressure. T1, $10 \mathrm{~min}$ after anesthesia induction under supine position; T2, $30 \mathrm{~min}$ after initiation of carbon dioxide $\left(\mathrm{CO}_{2}\right)$ pneumoperitoneum and Trendelenburg position; T3, 60 min after initiation of $\mathrm{CO}_{2}$ pneumoperitoneum and Trendelenburg position; T4, 10 min after $\mathrm{CO}_{2}$ desufflation and resuming the supine position.
Table 3. Respiratory mechanics measured at each time point

\begin{tabular}{|c|c|c|c|}
\hline & $\begin{array}{l}\text { PCV with VG Group } \\
(\mathrm{n}=39)\end{array}$ & $\begin{array}{l}\text { ERV Group } \\
(\mathrm{n}=39)\end{array}$ & Pvalue \\
\hline Ppeak $\left(\mathrm{cm} \mathrm{H}_{2} \mathrm{O}\right)$ & & & $0.909 a$ \\
\hline $\mathrm{T} 1$ & 14 [13 - 15] & 14 [13 - 15] & 0.811 \\
\hline $\mathrm{T} 2$ & $28[26-32]$ & $29[27-33]$ & 0.113 \\
\hline $\mathrm{T} 3$ & 27 [25 - 29] & $28[26-30]$ & 0.121 \\
\hline $\mathrm{T} 4$ & 17 [16 - 19] & 18 [17-19] & 0.275 \\
\hline Pplat $\left(\mathrm{cm} \mathrm{H}_{2} \mathrm{O}\right)$ & & & $0.917 \mathrm{a}$ \\
\hline $\mathrm{T} 1$ & 13 [12 - 14] & 13 [12 - 15] & 0.859 \\
\hline $\mathrm{T} 2$ & $28[26-30]$ & $29[26-32]$ & 0.262 \\
\hline $\mathrm{T} 3$ & 27 [25 - 29] & $27[24-30]$ & 0.369 \\
\hline $\mathrm{T} 4$ & 16 [14 - 17] & 16 [14 - 17] & 0.895 \\
\hline Pmean $\left(\mathrm{cm} \mathrm{H}_{2} \mathrm{O}\right)$ & & & $0.038^{a}$ \\
\hline $\mathrm{T} 1$ & $4.0[4.0-4.3]$ & $4.0[4.0-4.0]$ & 0.625 \\
\hline $\mathrm{T} 2$ & $9.0[8.0-9.0]$ & 10.0 [9.0 - 11.0] & $<0.001$ \\
\hline $\mathrm{T} 3$ & $9.0[7.8-9.3]$ & 10.0 [9.0 - 10.0] & 0.002 \\
\hline $\mathrm{T} 4$ & $5.0[4.0-5.0]$ & $5.0[5.0-6.0]$ & 0.073 \\
\hline $\begin{array}{l}\text { Cstat (mL cm } \\
\left.\mathrm{H}_{2} \mathrm{O}^{-1}\right)\end{array}$ & & & $0.203^{a}$ \\
\hline $\mathrm{T} 1$ & $41.2[37.0-45.1]$ & $43.4[36.7$ - 47.4$]$ & 0.313 \\
\hline $\mathrm{T} 2$ & $19.2[17.4$ - 21.6] & 18.1 [16.4 - 20.9] & 0.232 \\
\hline $\mathrm{T} 3$ & 21.0 [18.5 - 22.4] & 18.9 [16.8 - 21.0] & 0.127 \\
\hline $\mathrm{T} 4$ & 37.0 [32.1 - 39.9] & 35.7 [31.0 - 38.9] & 0.807 \\
\hline RR (breaths min $^{-1}$ ) & & & $0.015^{\mathrm{a}}$ \\
\hline $\mathrm{T} 1$ & 14 [13 - 15] & 14 [12 - 14] & 0.098 \\
\hline $\mathrm{T} 2$ & 17 [15 - 20] & 18 [16 - 20] & 0.839 \\
\hline $\mathrm{T} 3$ & 16 [14 - 18] & 17 [14 - 19] & 0.291 \\
\hline $\mathrm{T} 4$ & 16 [14 - 20] & 20 [18 - 20] & 0.038 \\
\hline
\end{tabular}

Data are presented as median (interquartile range). PCV with VG, pressure-controlled ventilation with volume guarantee; ERV, 1:1 equal ratio ventilation; Ppeak, peak inspiratory pressure; Pplat, plateau airway pressure; Pmean, mean airway pressure; Cstat, static compliance; RR, respiratory rate. T1, 10 min after anesthesia induction under supine position; T2, $30 \mathrm{~min}$ after initiation of carbon dioxide $\left(\mathrm{CO}_{2}\right)$ pneumoperitoneum and Trendelenburg position; $\mathrm{T} 3,60 \mathrm{~min}$ after initiation of $\mathrm{CO}_{2}$ pneumoperitoneum and Trendelenburg position; T4, $10 \mathrm{~min}$ after $\mathrm{CO}_{2}$ desufflation and resuming the supine position. ${ }^{\mathrm{a}} \mathrm{P}_{\mathrm{group}} \times$ time $=\mathrm{P}$ value of the group and time interaction obtained by linear mixed model analysis.

Table 4. Postoperative outcomes

\begin{tabular}{llll}
\hline & $\begin{array}{l}\text { PCV with VG } \\
\text { Group } \\
\text { (n= 39) }\end{array}$ & $\begin{array}{l}\text { ERV Group } \\
\text { (n= 39) }\end{array}$ & P value \\
\hline PACU time (min) & $48[36-54]$ & $45[38-60]$ & 0.813 \\
Postoperative fever & $8(20.5)$ & $11(28.2)$ & 0.429 \\
Postoperative hospital stay (d) & $3[2-4]$ & $2[2-4]$ & 0.275 \\
Readmission within 30 days & $3(7.7)$ & $3(7.7)$ & $>0.999$ \\
\hline
\end{tabular}

Data are presented as median (interquartile range) and numbers (\%). PCV with VG, pressure-controlled ventilation with volume guarantee; ERV, 1:1 equal ratio ventilation; PACU, postoperative anesthesia care unit.

\section{Discussion}

The objective of this study was to compare the effects of PCV with VG and ERV on gas exchange, respiratory mechanics and hemodynamics during RALP. Our results indicate that, although Pmean was reduced with PCV with VG 30 and $60 \mathrm{~min}$ after initiation of $\mathrm{CO}_{2}$ pneumoperitoneum and Trendelenburg position, no differences in oxygenation were observed between the PCV with VG and ERV group. Gas exchange, respiratory mechanics except Pmean, and hemodynamics were also comparable regardless of the ventilator mode used.

PCV with VG is a type of dual-controlled 
ventilation mode that combines the advantages of PCV and VCV. This new ventilation mode includes Autoflow ventilation (Dräger), PCV with volume guaranteed (PCV-VG; General Electric), and PRVC (Maquet), and has the potential to reduce inspiratory pressure and atelectasis [15]. Theoretically, dual-controlled ventilation is suitable for maintaining an appropriate tidal volume during laparoscopic surgery, where sudden changes in intra-abdominal pressure may occur because of $\mathrm{CO}_{2}$ pneumoperitoneum and position changes. Otherwise, frequent adjustments in the Ppeak would be required with PCV to provide adequate ventilation according to the changes in lung compliance [16]. Notwithstanding these theoretical advantages, however, many studies evaluating PCV with VG have been conducted as cross-over studies [16-18]. Thus, scant information is available to assess the superiority of PCV with VG including Autoflow ventilation over other ventilation modes during laparoscopic surgery.

The goals of anesthetic management in laparoscopic surgery are to maintain oxygenation and prevent barotrauma. Although many studies have suggested that ERV enhances oxygenation in patients with acute respiratory distress syndrome $[19,20]$, the effects of ERV on oxygenation during surgery remain controversial. In a meta-analysis of seven prospective trials involving one-lung ventilation or $\mathrm{CO} 2$ pneumoperitoneum, ERV significantly improved oxygenation at $60 \mathrm{~min}$ after intervention, but not at 20 or 30 min after intervention [12]. The main mechanism responsible for oxygen improvement by ERV is alveolar recruitment through an increased Pmean [21]. A higher Pmean allows collapsed alveoli to reopen in a manner similar to applying extrinsic PEEP; as a result, arterial oxygenation is improved and Ppeak is reduced [22,23]. Despite its theoretical benefits, ERV has the major drawback of possibly impeding venous return and reducing cardiac output. These hemodynamic effects limit widespread clinical application of ERV during surgery. Therefore, we conducted the present study to evaluate the hypothesis that PCV with VG ventilation might have clinical benefits during laparoscopic surgery if oxygenation or Ppeak are superior with PCV with VG, compared with ERV.

Contrary to our expectations, neither PCV with VG nor ERV demonstrated superiority for improving oxygenation in patients undergoing RALP. Pmean, which is a major determinant of arterial oxygenation, was slightly, but significantly lower in the PCV with VG group $\left(9 \mathrm{~cm} \mathrm{H}_{2} \mathrm{O}\right)$ compared to the ERV group (10 $\mathrm{cm} \mathrm{H}_{2} \mathrm{O}$ ). However, $\mathrm{PaO}_{2}$ was comparable between groups at $30 \mathrm{~min}$ after initiation of the Trendelenburg position and pneumoperitoneum, as well as throughout the study period. A possible explanation for the lack of difference in $\mathrm{PaO}_{2}$ between groups is that ERV improves oxygenation by increasing Pmean only when alveoli are recruitable. As Lee et al. presented in their study, $\mathrm{PaO}_{2}$ improved in patients with higher physiological dead space and better baseline gas exchange [13]. In addition, there is no further beneficial effect of increasing Pmean when total PEEP is constant and alveoli are sufficiently inflated [13,24]. Thus, when oxygenation was improved beyond the alveolar capacity, further improvement does not occur by increasing Pmean. This is supported by our results, which showed that $\mathrm{PaO}_{2}$ did not decrease during Trendelenburg positioning and $\mathrm{CO}_{2}$ pneumoperitoneum and was somewhat higher than values reported in previous studies with a similar design. Previously, Kim et al.[11] and Choi et al.[6] reported lower $\mathrm{PaO}_{2}$ levels during the Trendelenburg position and $\mathrm{CO}_{2}$ pneumoperitoneum than at $10 \mathrm{~min}$ after induction. In Kim et al's study [11], $\mathrm{PaO}_{2}$ was lowest (153-155 cm $\mathrm{H}_{2} \mathrm{O}$ ) during the Trendelenburg position in the 1:2 I/E ratio group with a higher Ppeak and lower Pmean, whereas in our study, $\mathrm{PaO}_{2}$ was highest during the Trendelenburg position and $\mathrm{CO}_{2}$ pneumoperitoneum with a relatively lower Ppeak and higher Pmean. Although Ppeak might not accurately reflect alveolar pressure when the flow pattern is modified [25], Ppeak is clinically a major determinant of alveolar pressure [26], and is related to the barotrauma. In our current study, PCV with VG reduced Ppeak as much as ERV. Therefore, the increase in $\mathrm{PaO}_{2}$ observed in the current study suggests that both PCV with VG and ERV are sufficient to recruit alveoli and reduce Ppeak during the Trendelenburg position and $\mathrm{CO}_{2}$ pneumoperitoneum.

A major issue in ventilatory strategies during RALP is maintaining a physiological arterial $\mathrm{CO}_{2}$ tension without using high airway pressures. During pneumoperitoneum, it may be difficult to continue to increase minute volume by increasing tidal volume or respiratory rate in response to an elevated $\mathrm{ETCO}_{2}$, as these maneuvers may causes lung hyperinflation or barotrauma $[9,27]$. Strikingly, no patients in the current study exhibited a Ppeak greater than $40 \mathrm{~cm}$ $\mathrm{H}_{2} \mathrm{O}$ and all patients maintained an $\mathrm{ETCO}_{2}$ between 35 and $45 \mathrm{mmHg}$ during surgery. Although $\mathrm{PaCO}_{2}$ increased after the supine position was resumed at the end of surgery in the ERV group, the $\mathrm{pH}$ remained in the normal range and no clinical effects were observed. Together, our findings of improved oxygenation and maintained normocapnia without increased airway pressures suggest that both PCV with VG and ERV might be useful ventilator modalities during RALP. 
Patients undergoing RALP are usually elderly, with multiple coexisting diseases and reduced cardiovascular reserve. These patients are vulnerable to hemodynamic changes, and even small changes in cardiac output may result in substantial hemodynamic effects. Thus, ventilatory strategies to minimize impairment of cardiac function are necessary. As mentioned previously, increases in Pmean during ERV improve oxygenation, but reduce venous return and cardiac output by increasing intrathracic pressure [24]. Although no cardiovascular collapse were noted in our patients, our findings suggest that PCV with VG may be a more clinically appropriate and easier mode of ventilation than ERV - especially for patients with cardiopulmonary disease-because PCV with VG maintains oxygenation effectively as ERV, without increasing Pmean.

Taken together, results of our study revealed that PCV with VG was similar to ERV in maintaining oxygenation with lower Pmean during RALP. These results are consistent with the previous studies that compared PCV with VG to PCV or VCV in that PCV with VG lowered Ppeak or Pmean while maintaining similar oxygenation [16-18]. In other words, use of PCV with VG provides tight control on tidal volume and adequate oxygenation with a better compromise towards peak inspiratory pressure [28]. Therefore, it is concluded that the use of PCV with VG might be helpful in patients vulnerable to changes in airway pressure and indicated for ERV. In particular, PCV with VG might be suitable for patients with underlying diseases such as COPD and patients undergoing laparoscopic surgery or one lung ventilation, without concerns of hemodynamic instability or possibility of autoPEEP.

This study has several limitations. First, duration of PCV with VG or ERV were as short as 60 minutes because duration of Trendelenburg position was about 60 minutes. Considering that alveolar recruitment does not occur immediately after application of a specific ventilator mode and oxygenation improvement may be time dependent [24], a longer operative time may have produced different results. Second, our study did not include patients with respiratory disease or obesity, both of which are important factors for compromising oxygenation and respiratory mechanics. Third, patients were ventilated without the use of extrinsic PEEP, and we could not measure auto-PEEP during surgery, because measurement of auto-PEEP requires an end-expiratory hold [29].

In conclusion, during RALP, PCV with VG is an acceptable alternative ventilatory strategy to ERV for achieving similar levels of oxygenation. Indeed, oxygenation improved with both types of ventilation, suggesting that both ventilatory methods are suitable for RALP. However, PCV with VG produced lower Pmean values, suggesting that it may be more useful than ERV in patients with reduced cardiovascular function. Regardless of ventilation mode, careful monitoring is necessary to maintain adequate oxygenation, ventilation, and airway pressures during the Trendelenburg position and $\mathrm{CO}_{2}$ pneumoperitoneum phase of RALP.

\section{Acknowledgements}

Assistance with the study: The authors would like to thank Dr. Young Deuk Choi in the Department of Urology at the Yonsei university college of medicine for his helpful advice for this manuscript.

\section{Competing Interests}

The authors have declared that no competing interest exists.

\section{References}

1. Menon M, Shrivastava A, Tewari A. Laparoscopic radical prostatectomy: conventional and robotic. Urology 2005; 66(5 Suppl):101-4.

2. Hu JC, Gu X, Lipsitz SR, Barry MJ, D'Amico AV, Weinberg AC, et al Comparative effectiveness of minimally invasive vs open radical prostatectomy. JAMA 2009; 302(14):1557-64.

3. Falabella A, Moore-Jeffries E, Sullivan MJ, Nelson R, Lew M. Cardiac function during steep Trendelenburg position and $\mathrm{CO} 2$ pneumoperitoneum for robotic-assisted prostatectomy: a trans-oesophageal Doppler probe study. Int J Med Robot 2007; 3(4):312-5.

4. Kalmar AF, Foubert L, Hendrickx JF, Mottrie A, Absalom A, Mortier EP, et al. Influence of steep Trendelenburg position and $\mathrm{CO} 2$ pneumoperitoneum on cardiovascular, cerebrovascular, and respiratory homeostasis during robotic prostatectomy. British journal of anaesthesia 2010; 104(4):433-9.

5. Lestar M, Gunnarsson L, Lagerstrand L, Wiklund P, Odeberg-Wernerman S. Hemodynamic perturbations during robot-assisted laparoscopic radical prostatectomy in 45 degrees Trendelenburg position. Anesth Analg 2011; 113(5):1069-75

6. Choi EM, Na S, Choi SH, An J, Rha KH, Oh YJ. Comparison of volume-controlled and pressure-controlled ventilation in steep Trendelenburg position for robot-assisted laparoscopic radical prostatectomy. J Clin Anesth 2011; 23(3):183-8

7. Andersson LE, Baath M, Thorne A, Aspelin P, Odeberg-Wernerman S. Effect of carbon dioxide pneumoperitoneum on development of atelectasis during anesthesia, examined by spiral computed tomography. Anesthesiology 2005; 102(2):293-9.

8. Ogurlu M, Kucuk M, Bilgin F, Sizlan A, Yanarates O, Eksert S, et al. Pressure-controlled vs volume-controlled ventilation during laparoscopic gynecologic surgery. J Minim Invasive Gynecol 2010; 17(3):295-300.

9. Kim WH, Hahm TS, Kim JA, Sim WS, Choi DH, Lee EK, et al. Prolonged inspiratory time produces better gas exchange in patients undergoing laparoscopic surgery: A randomised trial. Acta Anaesthesiol Scand 2013; 57(5):613-22.

10. Kim SH, Choi YS, Lee JG, Park IH, Oh YJ. Effects of a 1:1 inspiratory to expiratory ratio on respiratory mechanics and oxygenation during one-lung ventilation in the lateral decubitus position. Anaesth Intensive Care 2012; 40(6):1016-22.

11. Kim MS, Kim NY, Lee KY, Choi YD, Hong JH, Bai SJ. The impact of two different inspiratory to expiratory ratios (1:1 and 1:2) on respiratory mechanics and oxygenation during volume-controlled ventilation in robot-assisted laparoscopic radical prostatectomy: a randomized controlled trial. Can J Anaesth 2015; 62(9):979-87.

12. Park JH, Lee JS, Lee JH, Shin S, Min NH, Kim MS. Effect of the Prolonged Inspiratory to Expiratory Ratio on Oxygenation and Respiratory Mechanics During Surgical Procedures. Medicine (Baltimore) 2016; 95(13):e3269.

13. Lee SM, Kim WH, Ahn HJ, Kim JA, Yang MK, Lee CH, et al. The effects of prolonged inspiratory time during one-lung ventilation: a randomised controlled trial. Anaesthesia 2013; 68(9):908-16.

14. Brower RG, Matthay MA, Morris A, Schoenfeld D, Thompson BT, Wheeler A. Ventilation with lower tidal volumes as compared with traditional tidal volumes for acute lung injury and the acute respiratory distress syndrome. New England Journal of Medicine 2000; 342(18):1301-8. 
15. Kim H. Protective strategies for one-lung ventilation. Korean journal of anesthesiology 2014; 67(4):233-4.

16. Dion JM, McKee C, Tobias JD, Sohner P, Herz D, Teich S, et al. Ventilation during laparoscopic-assisted bariatric surgery: volume-controlled, pressure-controlled or volume-guaranteed pressure-regulated modes. Int J Clin Exp Med 2014; 7(8):2242-7.

17. Song SY, Jung JY, Cho MS, Kim JH, Ryu TH, Kim BI. Volume-controlled versus pressure-controlled ventilation-volume guaranteed mode during one-lung ventilation. Korean J Anesthesiol 2014; 67(4):258-63.

18. $\mathrm{Pu} \mathrm{J}$, Liu Z, Yang L, Wang $\mathrm{Y}$, Jiang J. Applications of pressure control ventilation volume guaranteed during one-lung ventilation in thoracic surgery. Int J Clin Exp Med 2014; 7(4):1094-8.

19. Marcy TW, Marini JJ. Inverse ratio ventilation in ARDS. Rationale and implementation. Chest 1991; 100(2):494-504.

20. Zavala E, Ferrer M, Polese G, Masclans JR, Planas M, Milic-Emili J, et al. Effect of inverse I:E ratio ventilation on pulmonary gas exchange in acute respiratory distress syndrome. Anesthesiology 1998; 88(1):35-42.

21. Yanos J, Watling SM, Verhey J. The physiologic effects of inverse ratio ventilation. Chest 1998; 114(3):834-8.

22. Lee $\mathrm{K}, \mathrm{Oh} \mathrm{YJ}$, Choi YS, Kim SH. Effects of a 1:1 inspiratory to expiratory ratio on respiratory mechanics and oxygenation during one-lung ventilation in patients with low diffusion capacity of lung for carbon monoxide: a crossover study. J Clin Anesth 2015; 27(6):445-50.

23. Marini JJ, Ravenscraft SA. Mean airway pressure: physiologic determinants and clinical importance--Part 2: Clinical implications. Crit Care Med 1992; 20(11):1604-16

24. Lessard MR, Guerot E, Lorino H, Lemaire F, Brochard L. Effects of pressure-controlled with different I:E ratios versus volume-controlled ventilation on respiratory mechanics, gas exchange, and hemodynamics in patients with adult respiratory distress syndrome. Anesthesiology 1994; 80(5):983-91.

25. Milic-Emili J, Tantucci C, Chassé M, Corbeil C. Introduction with special reference to Ventilator-associated Barotrauma. Pulmonary Function in Mechanically Ventilated Patients: Springer; 1991: 1-8.

26. Kilpatrick B, Slinger P. Lung protective strategies in anaesthesia. Br J Anaesth 2010; 105 Suppl 1:i108-16.

27. Park EY, Koo BN, Min KT, Nam SH. The effect of pneumoperitoneum in the steep Trendelenburg position on cerebral oxygenation. Acta Anaesthesiol Scand 2009; 53(7):895-9.

28. Ball L, Dameri M, Pelosi P. Modes of mechanical ventilation for the operating room. Best Pract Res Clin Anaesthesiol 2015; 29(3):285-99.

29. Mughal MM, Culver DA, Minai OA, Arroliga AC. Auto-positive end-expiratory pressure: mechanisms and treatment. Cleve Clin J Med 2005; 72(9):801-9. 